\title{
Research Progress of Coal Damage under Unsteady Load in China
}

\author{
Xi Chen $\mathbb{D}$, Guoliang Ma $\mathbb{D}$, Chaonan Fan, and Shaocheng Ge \\ College of Safety and Emergency Management Engineering, Taiyuan University of Technology, Taiyuan 030024, China \\ Correspondence should be addressed to Xi Chen; chenxi01@tyut.edu.cn
}

Received 10 August 2021; Accepted 30 September 2021; Published 12 October 2021

Academic Editor: Xin Liang

Copyright (C) 2021 Xi Chen et al. This is an open access article distributed under the Creative Commons Attribution License, which permits unrestricted use, distribution, and reproduction in any medium, provided the original work is properly cited.

Coalbed methane mining, suppression of coal dust, and elimination of dynamic disasters are closely related to the expansion of coal body cracks and internal damage. Understanding the expansion mechanism of pore-cracks is critical to investigate coal body damage. In this study, research from 2016 to 2021 conducted on the coal damage mechanism in China was sorted and the progress in this field was analysed to systematically investigate coal body damage. Critical topics of research in this field in recent years were identified, and load types were classified into static and dynamic loads. Dynamic loads with obvious characteristics and considerable damage-increasing effects were classified into impacting, cyclic, pulsating, and other dynamic load types. The current load-generating devices, various detection techniques and methods, research results, and the future research directions under various load types were discussed. The current coal damage research is primarily based on macrocharacteristic analysis and the stage characteristics of characterisation variables. The use of scanning electron microscopy, computerised tomography three-dimensional reconstruction technology, and acoustic emission technology can reveal the pore propagation mechanism at the micro level.

\section{Introduction}

Gas and coal dust are recognised as the five major types of disasters in coal mining. Excessive concentration of gas and coal dust not only poses an explosion risk but also creates a harsh working environment for workers [1]. With the stringent implementation of rules and regulations and improvement of safety management levels, the number of gas and coal dust explosion accidents has reduced considerably [2]. Safe production of coal mines and working environment of coal mine workers, elimination of gas disasters, and improvement of gas drainage efficiency are critical in coal mining.

Coal damage research is mostly focused on gas drainage and dust control. To improve the efficiency of gas drainage and underground working environments, considerable research has been conducted on coal damage mechanisms. These studies advocate artificially promoted coal damage. The change of coal mechanical properties and the propagation mechanism of pore-cracks under various loads are critical research directions in coal mining. Promoting the expansion and development of coal pore-cracks is conducive to increasing the fluid flow, improving the efficiency of coalbed methane extraction, and developing geothermal mine resources [3]. Numerous studies have been conducted on the distribution and development of coal cracks. In the 1950s, Hobbs, Evans and Pomeroy, and Murrell conducted experimental research on the damage state of coal under uniaxial compression and triaxial compression [4-7]. To study the properties and structure of coal, Van der Merwe, Terry, and Bieniawski did not limit their study to small coal samples and performed extensive studies on large coal samples [8-11].

After the 1980s, researchers in China [12-16] began to study the mechanical properties of coal and considered the degree of metamorphism, axial pressure, confining pressure, gas pressure, temperature, coal mechanical properties, damage evolution characteristics, and damage morphology. Xie et al. and Zhou et al. [17-19] analysed coal damage, coal permeability improvement, coal and rock mining dynamics, and coal and rock combination damage under various typical mining methods and investigated the characteristics 
of coal and rock crack propagation, stability, and increase in permeability under different mining conditions.

With the ever-increasing demand for high-efficiency gas extraction and safe working environments in mines, numerous methods and technologies for promoting coal body damage and crack propagation have emerged. Research on coal body damage has become a research hot spot. This article searched and organised research from 2016 to 2021 on "coal damage," as displayed in Figure 1. Research on coal body damage is primarily focused on three aspects: characteristics, load, and environment. The characteristic parameters mainly include stress, permeability, and porosity. The change of characteristic parameters reflects the effect and degree of coal damage and macroscopically reveals the generation and expansion of fracture pores. The type and action mode of the load mainly affect the changes in characteristic parameters. The action mode is mainly categorised into mechanical and hydraulic modes (including fracturing fluids, such as water, liquid nitrogen, and liquid carbon dioxide). Impacting, cycling, and pulsating are some load types. Furthermore, appropriate failure methods should be selected in various environments. The temperature, humidity, and gas content considerably affect coal failure. Under the comprehensive action of characteristics, load, and environment, pore-cracks and deformation expand and coal failure occurs. Coal pores determine the mechanical properties of coal and affect the seepage and drainage of coalbed methane. The pore fracture structure affects the gas flow behaviour, and the well-connected pore fracture network can effectively promote the gas flow $[20,21]$. Most coal body damage is investigated under various load types, such as static and dynamic loads. Dynamic loads can be categorised into various load types. Various monitoring technologies and methods, such as original monitoring of the concentration of underground dust, strain analysis, acoustic emission (AE) analysis, permeability analysis, nuclear magnetic resonance (NMR) analysis, and energy analysis have been proposed. Among these, AE analysis is widely used.

\section{Coal Body Damage}

Coal is produced under the action of complex geological structures. Plant debris undergoes numerous complex biochemical and physical chemistry actions to form coal after peatisation and the coalification stages, as displayed in Figure 2. The pore structure of coal exhibits obvious characteristics of evolution, differentiation, and inheritance, which increases with the metamorphism degree [22].

The primary pores and secondary fissures in the formation process of coal are irregular and complex and are an anisotropic heterogeneous medium [23]. Coal body damage is caused by the development of internal pore-cracks under the action of external force, which changes its mechanical properties. The generation and expansion mechanism of pore-cracks are critical factors of coal body damage. Applying an external load is the conventional method to promote the development of pores and cracks in coal. Loads can be categorised into mechanical loads and hydraulic loads. Mechanical loads rely on external high-pressure or impact force to impact coal. Primary cracks close gradually after loading on the coal body, and the coal body produces elasticity and a few plastic deformations. After the load gradually exceeds the compressive strength of the coal body, large pores and cracks are formed and cracks and fractures occur, as displayed in Figure 3.

For hydraulic loads, after the pressure water enters the coal body, first, the surface of the coal body becomes wet. Under continuous pressure, the pressure water causes the pore network of the coal body to open, expand, and extend [24-27], as displayed in Figure 4. The pressure water flows in the pore-cracks and applies loads to the coal in multiple directions, which is more effective than mechanical loads for promoting the propagation of pore-cracks. Hydraulic loading not only promotes the flow of coalbed methane inside the coal body but also can infiltrate the coal body and inhibit dust production. Therefore, hydraulic load is a better choice for a high-gas mine [28].

\section{Research on Coal Damage under Unsteady Load}

The load on the coal body can be categorised into two categories, namely, static and dynamic loads. With further research and improvement of coal seam penetration, conventional static loads cannot be applied and the focus on the current research is on dynamic load. Critical factors, such as impacting load, pulsating load, and cyclic loading, are typically investigated (Figure 5).

3.1. Research on Coal Damage under Impacting Load. Pillars and coal bodies are susceptible to the effects of blasting, mechanical, and other dynamic loads on coal mining. Studies have simplified the related problems on the dynamic impact on coal and rock damage, that is, the effects of the impact load on coal. Primary cracks subsequently develop into macroscopic cracks [29].

Numerous methods have been proposed to comprehensively study the damage of coal under impacting load. The application of strain analysis is a critical method to describe coal damage. The application of numerical simulation methods can help understand the internal damage of coal to a certain extent.

For the analysis of the loading and unloading stage of coal damage, the coal forms internal damage and energy accumulation during loading should be investigated. During unloading, the internal energy release of coal causes rapid damage to coal. Therefore, the development of an efficient impact waveform is a critical research problem. Li et al. [30] conducted experiments on the propagation of stress waves in the elastoplastic combination of coal body distributed in front of the driving roadway under the impact load and determined the unloading wave formed under the impacting load which caused tensile stress in the coal body, which could cause the coal body to undergo rapid damage. Macroscopically, the tensile failure of coal and high-impact load is the main factor of this phenomenon [31].

$\mathrm{Mu}$, Wang, and others used numerical simulation methods to study coal damage under impacting load. 


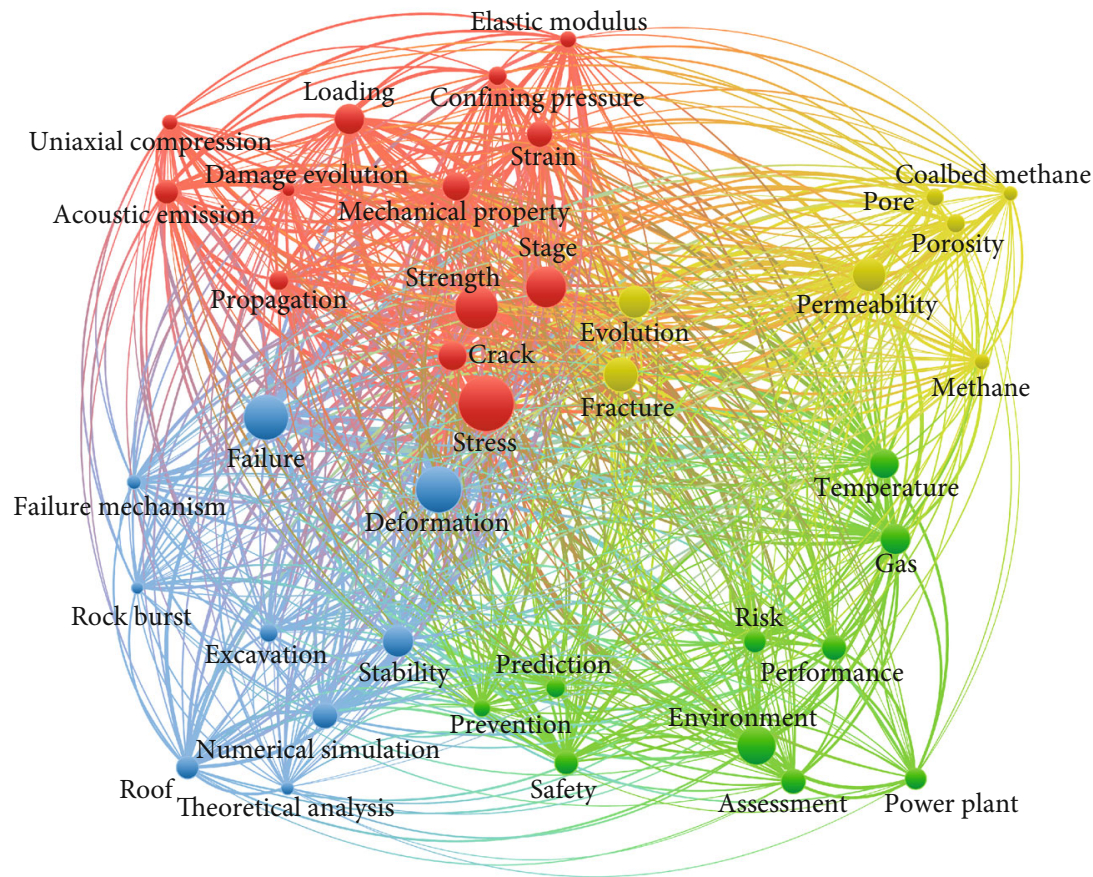

FIgURE 1: Distribution of research hot spots on coal body damage.

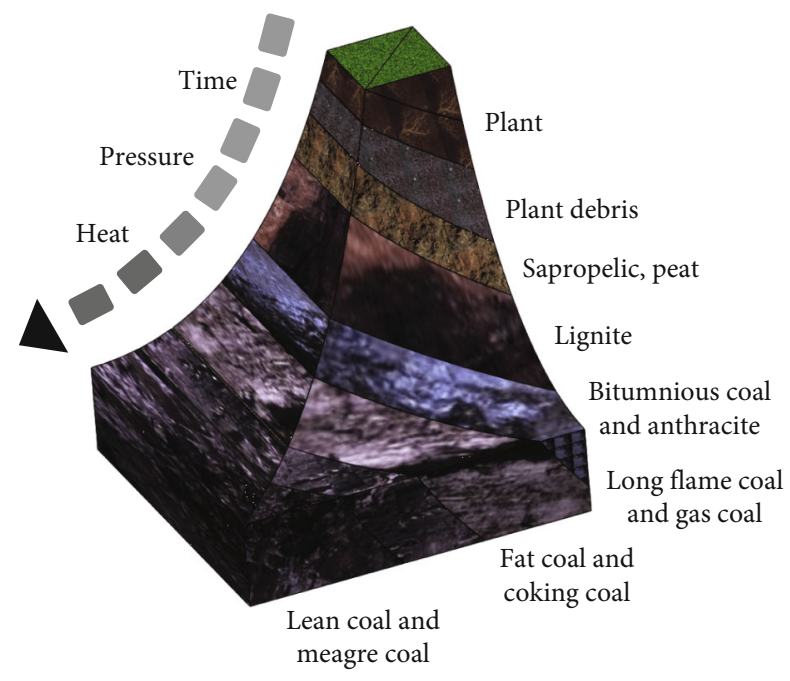

FIgURE 2: Coal formation stages.

Among them, Mu and Gong [32] improved the Zhu-WangTang constitutive model to reflect the strain rate effect and damage characteristics of the coal body and used the finiteelement programme to simulate the impact load of the coal body under various peaks under impact load. The damage caused by the following is categorised into two categories, namely, "rapid jump" damage, which is caused by large tensile shear stress, and "slow stepped" damage, which is caused by the alternating tension-shear-compression-shear action. Wang et al. [29] used the finite-element software LSDYNA to investigate the deformation and damage charac- teristics of coal and rock under various constrained static loads and impact velocities and determined that coal damage increased with the increase in impact velocity and with the increase in constrained static load. Coal damage was first reduced and then remained unchanged. Studies have revealed that coal body damage has a cumulative effect. Zheng et al. [33,34] conducted finite element and discrete element analyses based on X-ray computed tomography (XCT) images of heterogeneous coal and rock. The direction and energy of the impacting load and mineral distribution of coal rock considerably affect coal damage. Thus, the results of the embedded finite element analysis revealed the same conclusion as that of the experiment, which indicated that the tensile stress formed by the load on the coal can cause rapid damage and that the coal damage under the impact load has an accumulative effect. The application of finite element analysis can effectively reduce the experimental workload and help investigating the damage effect and damage mechanism under various experimental parameters. However, the influencing factors of simulation are uncertain and incomplete. Laboratory experiments and field experiments are still a crucial part of investigating the coal damage mechanism.

Wang et al. and Zhang et al. [35, 36] mainly focused on the dynamic characteristics of the coal body. Both studies used the split Hopkinson pressure bar (SHPB) to perform the impacting load experiment of the coal body under triaxial compression. A simple schematic of SHPB is displayed in Figure 6. The stress-strain curves of the coal samples obtained in the two studies are nearly identical. Wang et al. described the process of decreasing-increasingdecreasing the slope of the stress-strain curve when the 


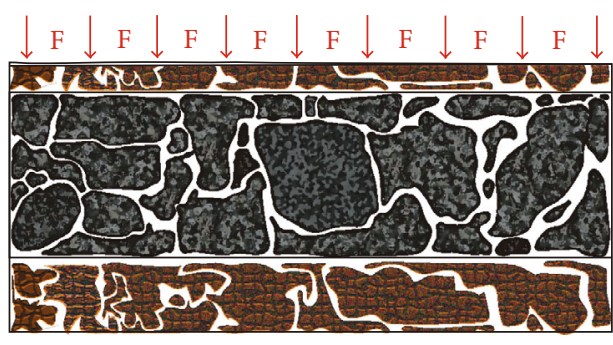

(a)

Mechanical external force acting on coal seam

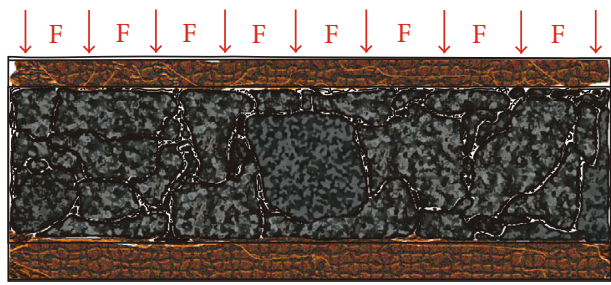

(d)

After the coal seam is loaded, the pores and cracks between the coal bodies are closed

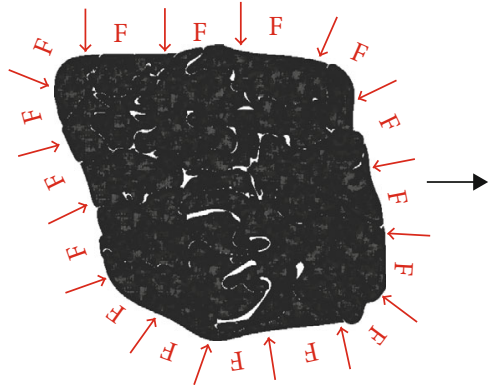

(b)

Loading of primary fracture

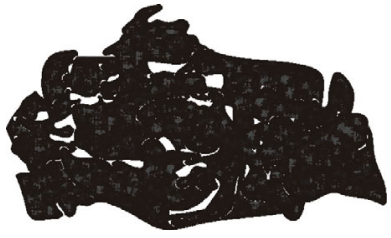

(e)

Coal body fractured and broken

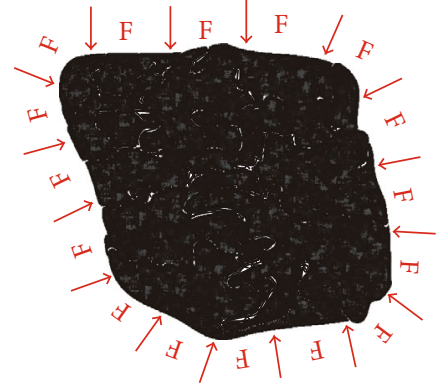

(c)

Closure of primary fissures

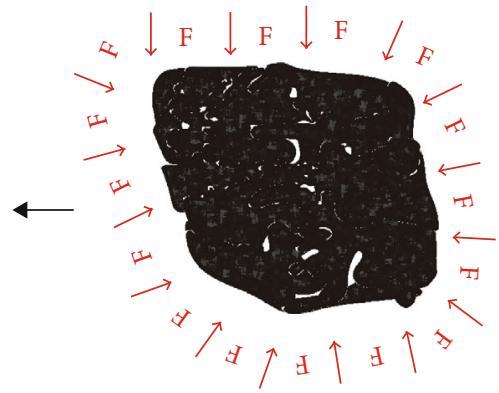

(f)

Development of secondary fissures

Figure 3: Development process of coal pore-cracks under mechanical loads.

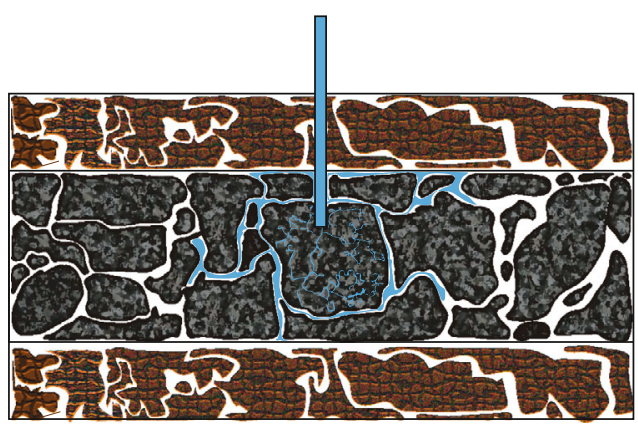

(a)

Water immersion in coal seam

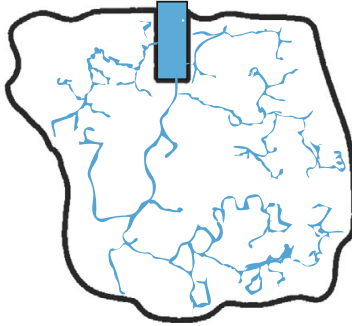

(b)

Effect of hydraulic load on primary pore of coal

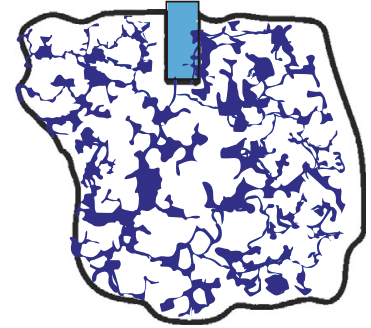

(c)

Pore development of coal under hydraulic load

FIgURE 4: Development process of coal pore-cracks under hydraulic loading.

stress reaches $60 \%-85 \%$ of the peak strength. According to the stress-strain curve, Zhang and others categorised coal damage into four stages, namely, no damage, microcrack evolution, macrocrack nucleation, macrocrack propagation, and collapse failure. For the damage constitutive model, Wang et al. comprehensively considered the impact load, static axial load, confining pressure, and other factors and selected the Drucker-Prager failure criterion in the coal body failure criterion to obtain the triaxial coal under the impacting load. The constitutive model of body damage is displayed in equation (1) [35]. Zhang et al. established the coal body damage constitutive model in stages, considering the first three stages and the fourth stage of coal body damage, as in equation (2) [36].

$$
\begin{gathered}
\sigma_{d}=E \varepsilon_{1} \exp \left[-\left(\frac{F}{F_{0}}\right)^{c}\right]-\sigma_{s}+2 v \sigma_{3}, \\
\sigma_{I}= \begin{cases}E_{D}\left(1-\left(\frac{\varepsilon_{I}}{\varepsilon_{s}}\right)^{n}\right) \varepsilon_{I}, & \varepsilon_{I}<\varepsilon_{I}^{B}, \\
\frac{\left(\Delta \sigma_{B C}\right)^{2}}{\left[\left(\varepsilon_{I}-\varepsilon_{I}^{B}\right) k_{B}+\Delta \sigma_{B C}\right]}, & \varepsilon_{I} \geq \varepsilon_{I}^{B} .\end{cases}
\end{gathered}
$$




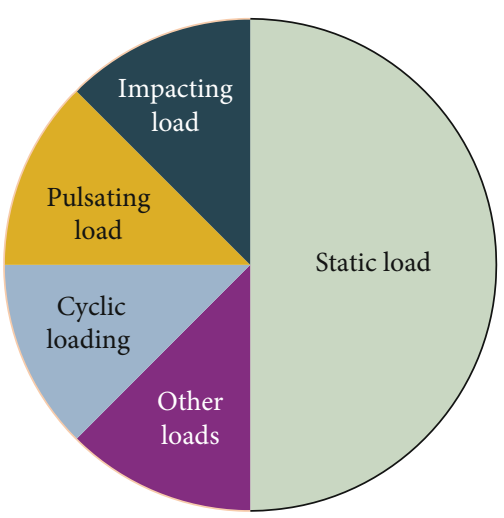

Figure 5: Distribution of the load type.

The crack growth of coal samples under impact load with various bedding dip angles differed considerably. Gong et al. and Minmin et al. $[37,38]$ used the SHPB to load the system (Figure 6). The dynamic crack growth rate and fractal characteristics of coals with various bedding under impact load differed considerably. The fractal crack growth rate of the $45^{\circ}$ bedding dip angle coal sample was the largest, and the damaging effect of the vertical bedding coal was superior to that of parallel bedding. Thus, the crack growth of coal samples with various bedding and dip angles was analysed comprehensively under impact load.

Zhao et al. and Wang et al. used the constrained pendulum impact dynamic loading device (Figure 7) for investigating coal samples. Zhao et al. [39-41] mainly focused on the quantitative characterisation of the degree of coal and rock damage. The amount of coal and rock damage is determined by the relationship between ultrasonic wave speeds and NMR T2 spectrum distribution. Under various static load conditions, the increasing impulse impact load of coal exhibits a tendency to accelerate damage. However, under a constant impulse, a low-axial pressure ratio results in a decelerated damage trend. A high-axial pressure ratio and no static load revealed a tendency to accelerate damage. As the number of impacts increases, the amount of damage to the coal body exhibits an inverted S-shaped accumulation growth model.

In the coal body impacting load experiment, mechanical force was used on the coal body. The axial compression ratio, impact force, and impulse cause coal body damage were studied. The results revealed that the high-axial compression ratio, high impact force, and incremental impulse effectively promote coal body damage. The single-factor analysis achieved excellent results, but it is yet to be determined whether the combined influence of factors, such as the axial compression ratio, impacting force, and impulse, can provide superior results. However, the multifactor analysis requires considerable experimental research and the large workload requires considerable financial and material resources. Thus, theoretical research is behind practice and determining the best coal damage conditions from the theoretical analysis is critical. The stress-strain curve also exhibits obvious stage characteristics, which lays the foundation for establishing the coal body damage constitutive model and can be used to investigate the ideal load condition based on the mathematical model.

3.2. Research on Coal Damage under Cyclic Loading. In coal mining, the coal body is disturbed by the periodic load because of the advance and stopping of working face and roof settlement, respectively. Cyclic loading affects the mechanical properties and long-term stability of coal. Extensive research has been conducted on coal damage under cyclic loading, and the AE technology has become a critical technical method for the quantitative characterisation of coal damage.

Jiang et al. [42] used a triaxial servo-controlled seepage metre and a PCI-2 AE system. First, the axial compression and confining pressure of $3 \mathrm{MPa}$ were applied and the axial stress was alternately loaded and unloaded at $0.05 \mathrm{MPa} / \mathrm{s}$ with increments of $2.5 \mathrm{MPa}$. Permeability exhibited a downward trend in the compaction stage and a slow downward trend in the elastic stage. Furthermore, permeability exhibited a slow downward trend in the yield stage, which increased sharply in the failure stage. Liu [43] revealed that the change of coal permeability under cyclic loading and unloading is categorised into three stages, namely, linear, exponential, and stable sections. The density of cracks and macropores can be used to determine the permeability and rate stress sensitivity. Li et al. [44] affirmed that the permeability changes of coal samples under cyclic loading present three-stage characteristics. Jiang et al. [42] revealed that with loading and unloading, the $\mathrm{AE}$ loop count rate and $\mathrm{AE}$ energy first slowly increased and subsequently increased rapidly in the yield stage and finally increased sharply in the destruction stage. The internal damage process of coal and rock exhibited obvious three-stage characteristics [45]. Zhong et al. [46] revealed that in the first loading cycle, the $\mathrm{AE}$ count increased with the increase in the loading amplitude; with the increase in the maximum loading amplitude and loading rate, the unloading process approached the minimum value of the cyclic loading. The event reappeared. Zhang et al. [47] conducted an incremental cyclic loading experiment on coal and determined that the changing trends of $\mathrm{AE}$ counts, energy, and events are consistent with the stress curve. During the cyclic loading process, the AE signal of the coal sample exhibited an obvious Kaiser effect. In another study, Zhang et al. [48] studied coal damage under cyclic loading by combining the AE technology and timespace dimensional cluster analysis and classified short-term damage based on time-space dimensional cluster analysis. Short links, middle links, and long links indicate local damage, overall damage, and random damage, respectively. Middle links exhibit the highest correlation to damage and destruction of coal. Jiang et al. [42] revealed that with incremental cyclic loading and unloading, the cumulative dissipation energy increased exponentially. Under layered cyclic loading, coal permeability, $\mathrm{AE}$, and energy dissipation change considerably as a result of the evolution of coal body damage. Li et al. [49] categorised the energy conversion before coal sample destruction into three stages, namely, initial energy accumulation, rapid accumulation, and rapid dissipation. 


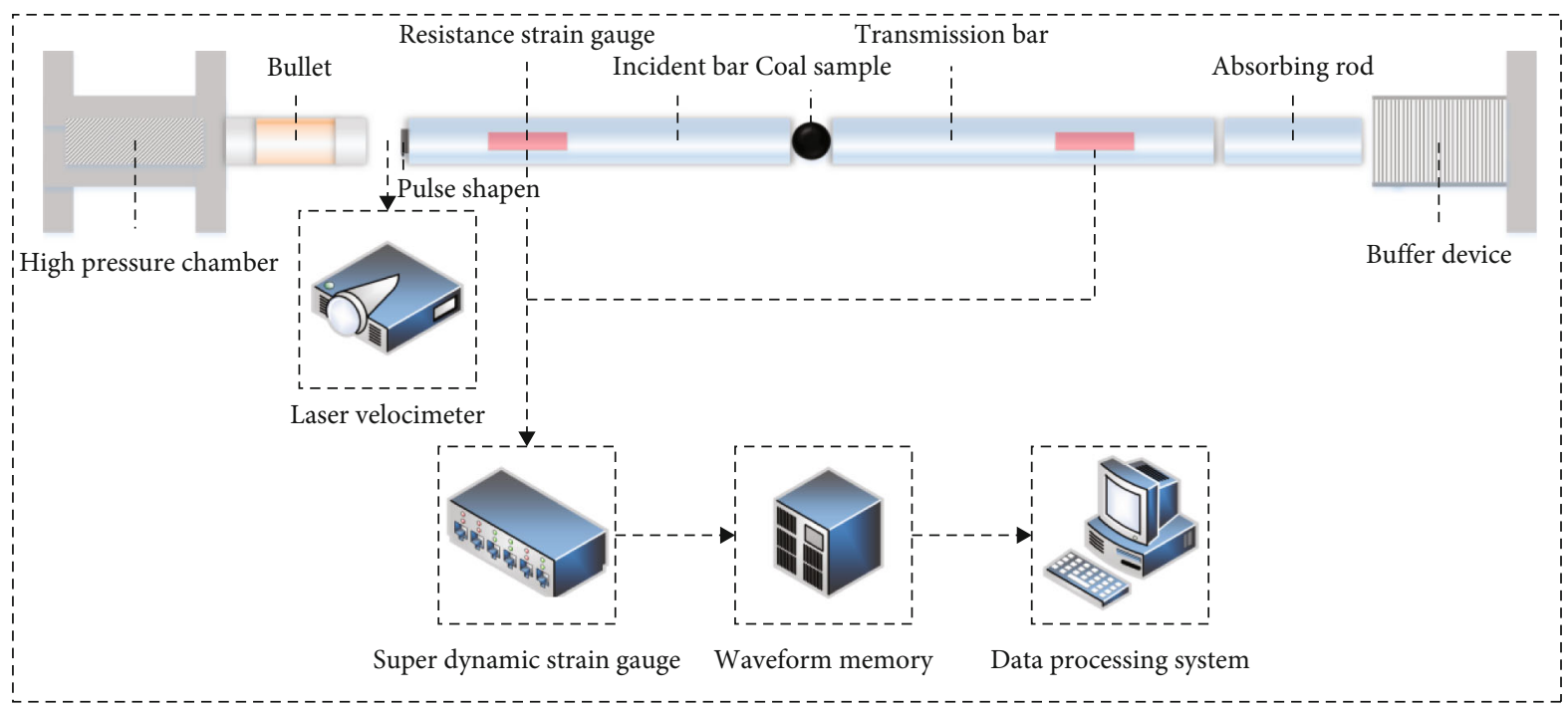

Figure 6: Split Hopkinson pressure bar (SHPB).
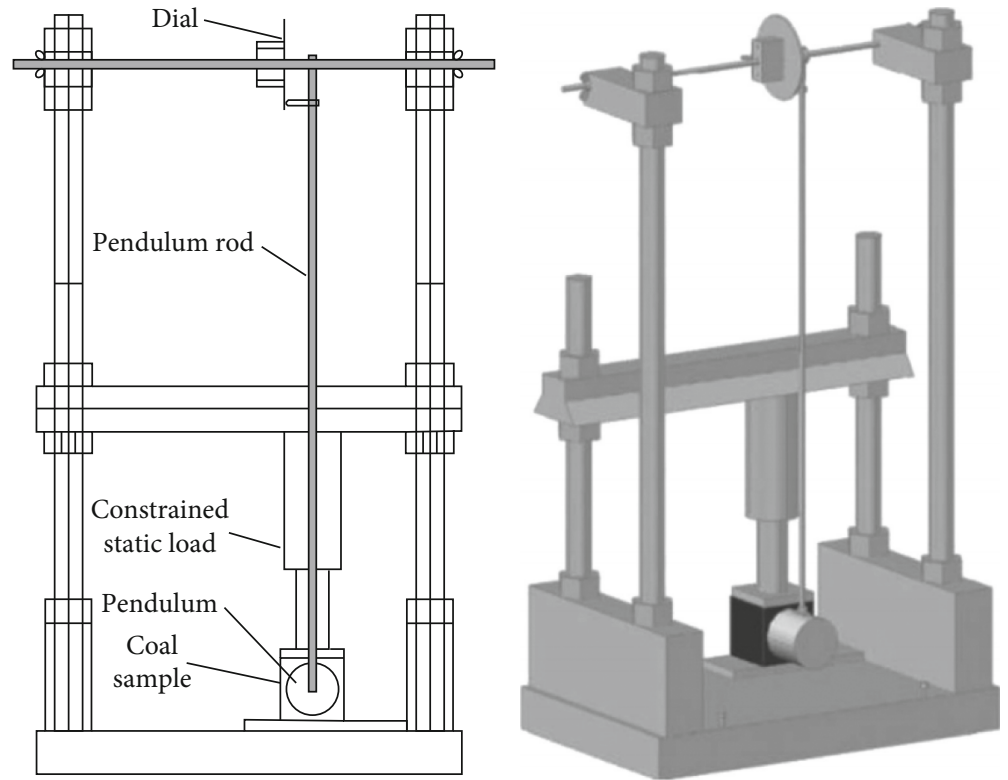

Figure 7: Constrained pendulum impact power loading device [29].

Zhong et al. [46] conducted an experimental study on the influence of pore water in coal under cyclic loading and revealed that in poorly connected pores, the increase in pore pressure causes the stress direction to rotate, resulting in tensile damage and pore compression. Pore water is released into the flat cracks, increasing the frictional resistance before the fractures slide. The NMR T2 distribution revealed that the pore water pressure changes the peak of the primary poorly connected pore size distribution and the high pore pressure destroys the hole wall. Zhang et al. [50] used NMR and revealed that the porosity of coal rock does not change considerably under low-amplitude cyclic loading, but when the pore fluid is discharged from the coal rock, the coal rock shrinks radially, causing residual shafts. The directional strain decreases; under the action of high- amplitude cyclic loading, the porosity increases considerably. The application of the NMR technology allows us to see the changes in coal porosity under load and study coal damage through the changes in pore size and porosity. Because of the repeated pressure change of the cyclic load, fatigue accumulation can effectively open closed pores, improve the porosity of coal, and change the strength of coal. Under regular loading, the coal damage exhibits phased changes. Xu et al. [51] revealed that under cyclic alternating hydraulic pressure, the damage evolution of coal is categorised into three stages, namely, the initial damage deformation stage, the cumulative damage deformation stage, and the accelerated damage deformation stage. Variable water pressure exhibits a cumulative effect and can limit the strength of coal and rock. Water is typically used as a 
fracturing fluid. Cold loading under certain conditions is still necessary for investigating coal body damage. Typically, liquid nitrogen is used as the fracturing fluid [52, 53]. Li et al. [54] used liquid nitrogen injection instead of water pressure to study the structural damage of coal samples subjected to cyclic cold loading and revealed that the degree of structural damage of the coal body exhibits a positive correlation with the cold loading cycle. The cold loading cycle is related to and considerably expanded the coal body's primary cracks. Cold and hot loading is relative to the research under some special situations. The damage law of coal under cold and hot loading is nearly identical to that under normal temperature loading. The law of crack propagation is mainly affected by the mechanical properties of coal and primary pore-crack, which is also a general law of coal damage. Therefore, the special damage mechanism under cold and hot loading should be investigated to improve production efficiency and eliminate disasters in a special environment.

Cyclic loading includes the mechanical load, hydraulic load, and liquid nitrogen injection. The effect of hydraulic load on increasing the permeability of coal is greater than that of the mechanical load, and hydraulic load promotes the expansion of cracks inside the coal. Cyclic loading can simulate periodic operation activities of mining working faces. Researchers can master the law of coal damage and the change of mechanical properties, which can eliminate hidden dangers of coal and gas outbursts. Cyclic loading causes fatigue damage to the coal body. The AE technology is used for observing coal body damage. $\mathrm{AE}$ can record the time-space location of coal body damage. Coal body stage damage can be a novel characterisation method. The relationship between primary cracks and cracks expansion is used in $\mathrm{AE}$ to determine the time-space location of cracks. However, AE cannot be used to confirm the reason for expansion. The NMR technology is used to investigate the size distribution of pores and to a certain degree can be used to supplement coal damage and the degree of development of pore-cracks. In various studies on the effect of coal cyclic loading, hydraulic cyclic loading is critical in mining of highgas coal mines.

3.3. Research on Coal Damage under Pulsating Load. The research of coal damage under pulsating load is primarily focused on two aspects, namely, the repeated action of pore water in the coal seam and the improvement of the cyclic loading pressure waveform. Pulsating hydraulic load can effectively increase the porosity of coal, promote the development of pores and cracks, and increase the gas permeability coefficient [28]. Impulsive loads can cause fatigue damage of coal and higher cracking and damage effects than conventional loads, which improve the permeability and mining conditions of coal $[55,56]$. Furthermore, it has been used in the research on coal damage in recent years.

The phased characteristics of coal damage are critical to understand the coal damage process. Zhu et al. [57-59] conducted numerous studies on coal body damage under the action of pulsating pore water pressure. The RLW-2000M coal and rock rheometer were used to generate the pulsating hydraulic pressure, as displayed in Figure 8. Under water

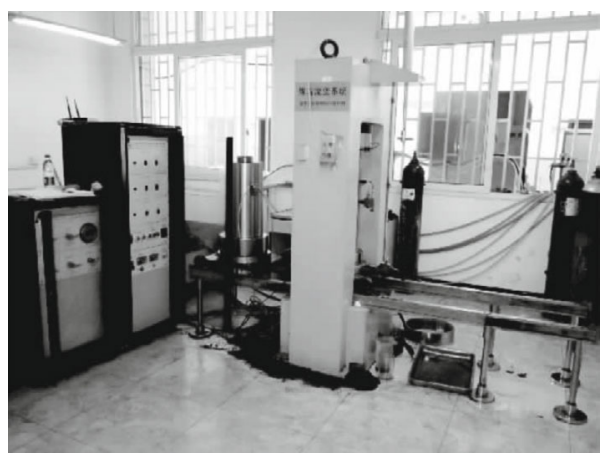

Figure 8: RLW-2000M coal and rock rheometer [58].

pressure, the coal sample exhibited fatigue failure and the strain curve revealed large deformation in the compact coupling stage, plastic deformation in the elastic coupling stage, and large slip deformation in the yield failure stage. In addition to this three-stage division of coal damage in the strain curve, $\mathrm{AE}$ data have also been considered in some studies. The AE technology can be used to realise the quantitative characterisation of coal damage through AE data, namely, the temporal and spatial evolution of coal damage. Studies have used AE data to describe coal damage in stages. Chen et al. and $\mathrm{Wu}$ et al. [60-62] used a true triaxial loading pulsating hydraulic fracturing test system to study coal damage, as displayed in Figure 9. Wu et al. categorised coal and rock damage into the following three stages according to the $\mathrm{AE}$ evolution: initial stage, damage development stage, and damage accelerated development stage. The three-stage characteristics of coal damage provide an excellent conclusion, which also corresponds to the macrocharacteristics of coal damage.

Pulsating frequency and pulsating peak pressure are two vital parameters of coal damage under pulsating load. Appropriate load parameters can promote coal damage. In the current research, the pulsating frequency and pulsating peak pressure are categorised into high and low levels, respectively. Ni et al. and Jingna et al. [63-65] studied the pore structure changes and overall damage of coal samples under pulsating hydraulic fracturing and used a pulsating water injection pump to generate the pulsating pressure, as displayed in Figure 10. The pore size and porosity were analysed by using mercury injection and liquid nitrogen adsorption methods. An energy spectrometer and scanning electron microscope were used to analyse the coal surface. The results revealed that the damage of pulsed load to coal was considerably higher than that of the static load effect by monitoring the adsorption and desorption of coalbed methane. For coal pores, the cumulative volume of micropores and its sum proportion are negatively correlated with the pulsation frequency and pressure; the large pores are positively correlated. The mesopores are positively correlated with the pulsation frequency. Furthermore, they revealed that low pressure and low frequency inhibited gas desorption, whereas low pressure and high frequency, high pressure and low frequency, and high pressure and high frequency promote the desorption of coalbed methane. They proposed that pulsating water exhibits corrosive effects, 


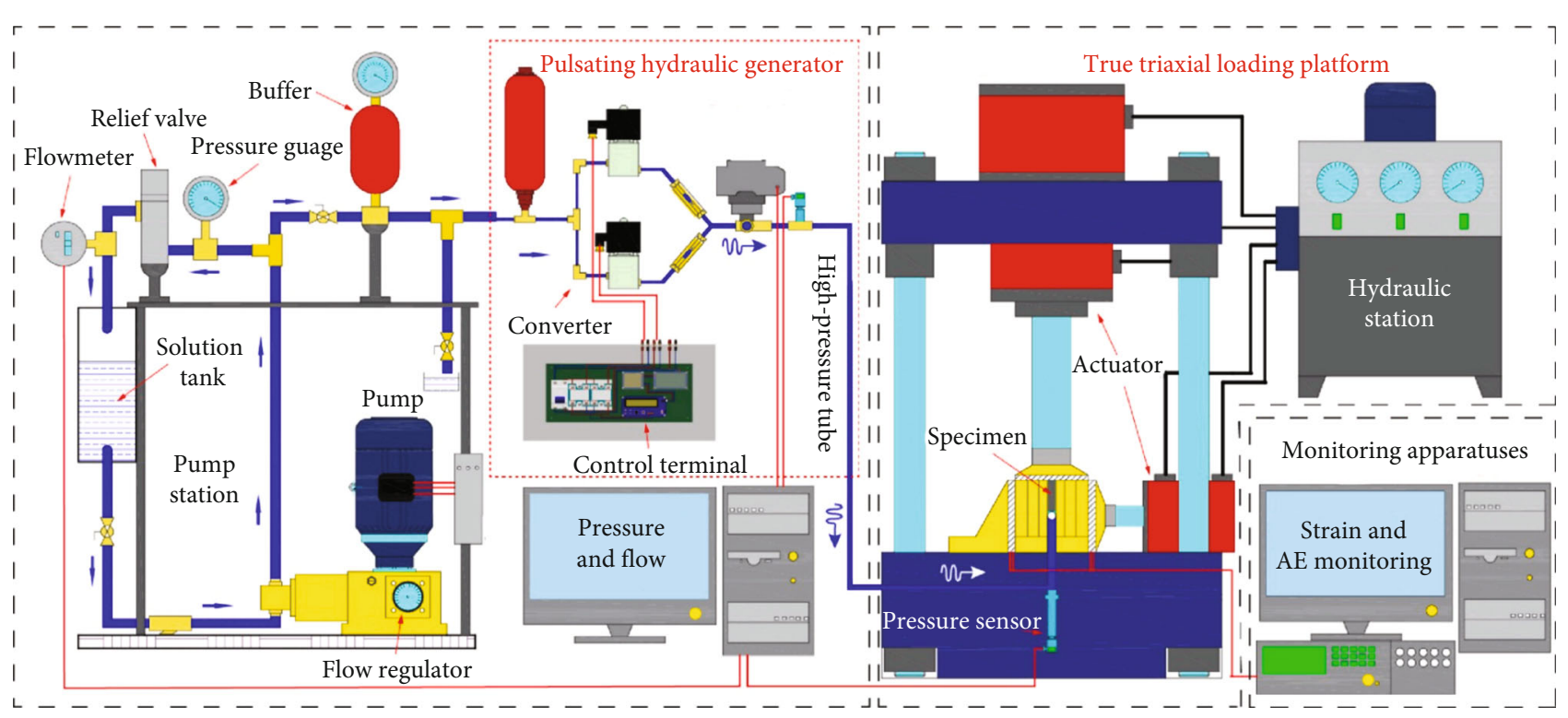

Figure 9: True triaxial loading pulsating hydraulic fracturing test system [52].

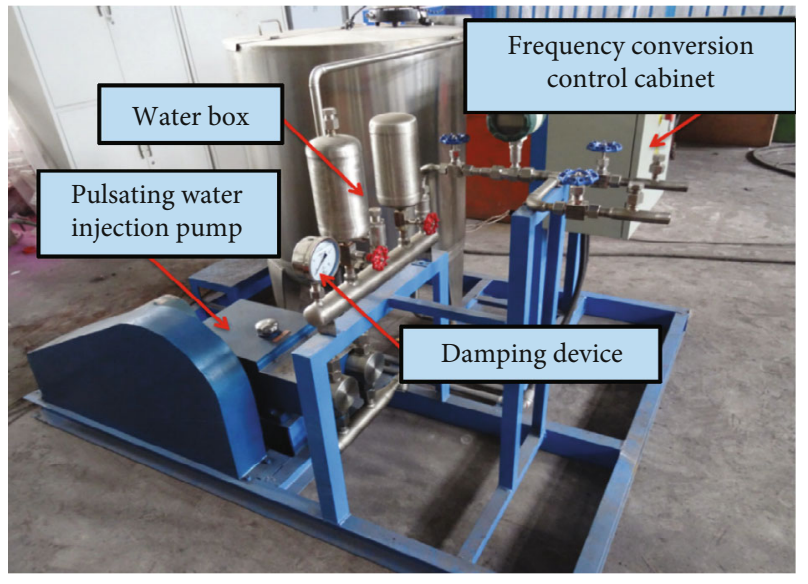

Figure 10: Experimental system diagram of pulsating water injection [65].

and pulsating peak pressure is the main factor that affects the fracturing radius. We can conclude that in addition to the low-pressure and low-frequency modes, the other three combinations can promote the damage of coal and the high-pressure and high-frequency modes are preferred to increase the damage. Furthermore, for pulsating pressure and pulsating frequency and the viscosity of fracturing fluid, a new factor was considered in the experiment. Wu et al. [61] revealed that low-frequency pulsation and lowviscosity fracturing fluid have a better effect on promoting fracture development. The next research direction is determining whether a better combination of pulsating pressure, pulsating frequency, and fracturing fluid viscosity can be found to achieve efficient coal loss increasing effect.

Fatigue damage accumulation of coal under pulsating load is consistent with the action mode of pulsating load and cyclic loading. The generation and action mechanisms of fatigue damage should be investigated and are related to eliminating the hidden danger of power disaster and enhancing the permeability of coal. Chen et al. [60] studied the fracture expansion of synthetic coal samples with preexisting cracks and revealed that the frequency and pressure amplitude exhibit a considerable effect on the fatigue damage of the coal body under the effect of pulsating load. They determined that pulsed gas load promotes the distribution of coal pores and the generation and transfer of smaller pores to large pores, forming a crossnetwork of cracks, which can effectively achieve penetration improvement. Hou et al. [66] did not use mechanical and hydraulic loads but instead used pulsed gas loads to observe the evolution of the coal pore structure and permeability changes and determined that pulsed gas loading can also cause coal body fatigue. They proposed a fatigue threshold of near 100 actions of pulsating load. Liu et al. [67] revealed that increasing the frequency or amplitude pressure of pulsed gas load can increase the pore volume and permeability of coal. In their approach, the "fatigue-induced fracturing effect" of pulse fracturing is used to produce irreversible deformation of coal pores and fissures.

The increasing frequency and decreasing pressure result in the initial crack expansion rate, and the pressure drop rate of the synthetic coal sample increases first and subsequently decreases, that is, a certain frequency and pressure can result in the best effect of coal body damage. Li et al. [68] revealed that the pulsating load can promote the formation of a better crack network in the coal body at low frequencies, but it can quickly produce cracks at high frequencies. They proposed that the graded pulse load exhibits superior working efficiency.

The use of the pulsating load base on cyclic loading results in better coal damage and pore expansion. The pulsating load is mostly hydraulic loads, and its focus is on the effects of pulsating frequency and pulsating pressure on coal damage. A higher pulsation frequency can increase the crack propagation rate, which mainly increases the number of fatigue damages of the coal body. The effect of a lower pulsation frequency on crack propagation is not ideal, but 
a better crack network will be formed under its action. However, the pressure waveform still exhibits defects and rapid pressure increase and rapid pressure relief result in the loss of a part of the pulsating hydraulic pressure. Because of the rapid arrival of pressure unloading during the pressurisation process, the hydraulic pressure cannot play a full role in coal. The new pulsating load (strong pressure loading-slow pressure unloading) exhibits a better effect of coal body damage and crack expansion.

3.4. Research on Coal Damage under Other Dynamic Loads. The effect of dynamic load causes considerable coal body damage. In addition to the aforementioned load methods with obvious characteristics, other types of dynamic loads have been also considered.

Under uniaxial compression, dynamic damage evolution, energy release, and $\mathrm{AE}$ are the key causes of coal damage and the effects of various factors on coal damage have been observed. The water content of coal considerably influences the mechanical properties of coal. An increase in the water content can effectively promote the coal damage. Kong et al. [69] analysed the AE technology and crack images at various stages and proposed that the primary fractures of coal affect its mechanical properties. Under uniaxial compression, the coal sample enters the plastic failure stage and the number of AEs increases markedly and new cracks form and expand. Thus, the AE technology can be used to effectively reflect the evolution of loading cracks. Lai et al. [70,71] conducted uniaxial compression experiments on water-bearing coal and rock and determined that the increase in the water content effectively reduced the mechanical properties of coal and rock, which is an effective method for promoting coal body damage, and it is also effective for the AE technology. The characterisation of coal damage evolution was verified and affirmed. Focusing on the hydraulic coupling effect, $\mathrm{Li}$ et al. [72] revealed that the combined water and free water in the coal and rock aggravate the damage and destruction and the increase of the water content can reduce the peak stress and brittleness of coal.

Various loading paths, loading and unloading rates, and loading areas of coal samples have been studied. Xu et al. [73] used three paths (increased axial compression and constant confining pressure, constant axial compression and unloading confining pressure, and increased axial compression and unloading confining pressure) to perform the loading experiment of coal. The result revealed that the combination of increasing the axial compression and unloading confining pressure is the best effect of coal body damage and permeability change. Liu et al. [74] studied coal damage under constant axial pressure and various unloading confining pressure rates and revealed that increasing the unloading rate results in a substantial increase in permeability and proposed that the change in coal permeability can be measured by increasing the crack length. Quantitative characterisation revealed that the increase in permeability is linearly related to the increase in the fracture length. Zhao et al. [75] studied the internal damage and crack evolution of coal samples under various loading areas. According to the relationship between ultrasonic wave speed and strain, the internal dam- age evolution of coal samples was categorised into three stages, namely, loading strengthening zone, loading weakening zone, and loading instability area. They found that changing the local load area does not change the threestage characteristics, but only affects the time of each stage. Chu et al. [76] considered coal body damage under explosive stress waves during coal mining and conducted laboratory research using explosives and ultrasonic detectors. They determined that as the number of explosive stress waves increases, the overall degree of coal body damage increases, the damage in the near area becomes pronounced, the greater stress intensity directly leads to the generation of cracks, and the middle and far areas promote the generation of coal cracks in the form of elastic waves. After the damage, the accumulated pores and cracks propagate and coal breaks occur.

In addition to the role of axial pressure and confining pressure, studies have considered the role of the gas pressure. Bai et al. [77] revealed that the increase of gas pressure increases the initial permeability of coal and rock mass. Rong et al. [78] indicated that under the constant effective confining pressure, the permeability of coal decreases with the increase in the gas pressure.

To investigate the mechanism of coal internal damage intuitively and systematically, the combination of CT three-dimensional reconstruction technology and numerical simulation can be used to obtain the characteristics of coal damage at each stage and the mechanism of crack propagation and effectively eliminate the influence of the difference in coal samples. Zhong et al. [79] used coal sample CT three-dimensional reconstruction and FLAC3D to study the damage evolution of deep coal. Wang et al. [80] characterised the pore structure of coal by three-dimensional CT reconstruction, NMR, and magnetic resonance imaging (MRI). Du et al. and Wang et al. [81, 82] first used the method of fractal dimension to affirm the validity and usability of CT scan images. The effective CT three-dimensional reconstruction of coal can be used to characterise the pore-crack structure which is a solution for studying the microscopic level of coal damage.

No systematic elaboration is available on the mechanism of coal damage and crack propagation. Most research results obtained at this stage are mainly based on macroscopic characteristics. The stress-strain curve, coal damage variable curve, and cumulative AE count and energy have stage characteristics. Gaps still exist in the understanding of the expansion of the microlevel cracks. The combination of scanning electron microscopy and CT three-dimensional reconstruction technology determines the validity of the microstructure of the coal model. The AE technology is used to monitor the spatiotemporal data of the generation and the expansion of coal pore-cracks and is combined with the microstructure of the coal model for microlevel analysis and establishing a damage theory and mathematical model describing the propagation of microscopic pores and cracks.

\section{Conclusion}

A thorough review of the research status of the coal damage mechanism and increase in permeability and dust removal in China in recent years was performed. The current 
research progress in this field was analysed. The article revealed the critical research directions in this field in recent years. Furthermore, the load types are categorised into two fields, namely, static and dynamic loads. Some of the dynamic loads with obvious characteristics and better damage-increasing effects are classified as impacting load, cyclic loading, pulsating load, and other dynamic load types. The current load-generating devices, various detection techniques and methods, and the crucial research results under various load types were reviewed. The AE technology, ultrasonic detectors, and stress-strain detection are widely used in the research of coal body damage. Coal and rock rheometers, three-axis servo-controlled seepage metres, separated Hopkinson pressure rods, restrained pendulum loading devices, and pulsating water injection pumps are widely used as load-generating devices. In coal damage, the impact of axial pressure, confining pressure, water content, and gas pressure on the damaging effect of coal is critical. The generation, expansion, and development of pore-cracks directly determine the degree of coal damage, and it is also related to coalbed methane. The efficiency of extraction and dust suppression is a critical research direction for the generation and expansion of pore-cracks. The microscopic mechanism of the generation and expansion of pore-cracks is still a crucial research direction. The combination of scanning electron microscopy, CT three-dimensional reconstruction technology, and acoustic emission technology may be the key to microscopic crack expansion.

\section{Conflicts of Interest}

The authors declare that they have no conflicts of interest.

\section{Acknowledgments}

This study is supported by the National Natural Science Foundation of China (Grant no. 52174195 and 51704145) and the Doctoral Startup Fund of Liaoning Province of China (Grant no. 20170520086) and also supported by the Transformation of Scientific and Technological Achievements Programs of Higher Education Institutions in Shanxi (Grant no. 2020CG022).

\section{References}

[1] L. Yan-qiang, Q. Yue-ping, Y. Xiao-bin, and T. Liang, "New progress on coal mine dust in recent ten years," Procedia Engineering., vol. 26, pp. 738-743, 2011.

[2] C. Zhang, E. Wang, Y. Wang, and X. Zhou, "Spatial-temporal distribution of outburst accidents from 2001 to 2020 in China and suggestions for prevention and control," Coal Geology and Exploration., vol. 49, no. 4, pp. 134-141, 2021.

[3] Z. Liu, M. Zhang, S. Yu, L. Xin, G. Wang, and L. Sun, "Experimental study on the fractal features and permeability characteristics of low metamorphic coal pore structure under thermal damage," Geofluids, vol. 2020, Article ID 8864571, 2020.

[4] D. W. Hobbs, "The strength and the stress-strain characteristics of coal in triaxial compression," The Journal of Geology, vol. 72, no. 2, pp. 214-231, 1964.
[5] D. W. Hobbs, "The strength and stress-strain characteristics of Oakdale coal under triaxial compression," Geological Magazine, vol. 97, no. 5, pp. 422-435, 1960.

[6] I. Evans and C. D. Pomeroy, "The strength of cubes of coal in uniaxial compression," in Mechanical Properties of NonMetallic Brittle Materials, W. H. Walton, Ed., pp. 5-28, Butterworths Scientific Publications, London, 1958.

[7] S. A. F. Murrell, "The strength of coal under triaxial compression," in Mechanical POroperties of Non-Metallic Brittle Materials, W. H. Walton, Ed., pp. 123-153, Butterworths Scientific Publications, London, 1958.

[8] J. N. Van der Merwe, "A laboratory investigation into the effect of specimen size on the strength of coal samples from different areas," Journal of the South African Institute of Mining and Metallurgy, vol. 103, no. 5, pp. 273-280, 2003.

[9] N. B. Terry, "The dependence of the elastic behaviour of coal on the microcrack structure," Fuel, vol. 103, no. 5, pp. 273 280, 1959.

[10] Z. T. Bieniawski, "In situ strength and deformation characteristics of coal," Engineering Geology, vol. 2, no. 5, pp. 325-340, 1968.

[11] Z. T. Bieniawski, "The effect of specimen size on compressive strength of coal," International Journal of Rock Mechanics and Mining Sciences \& Geomechanics Abstracts, vol. 5, no. 4, pp. 325-335, 1968.

[12] H. Zhao, G. Yin, and W. Zhang, "Study of creep characteristics and constitutive relation of briquette under confining pressure," Rock and Soil Mechanics., vol. 30, no. 8, pp. 23052308, 2009.

[13] Y. Yao and S. Zhou, "The mechanical property of coal containing gas," Journal of China University of Mining and Technology, vol. 4, no. 1, pp. 4-10, 1988.

[14] J. Xu, X. Xian, Y. Du, and G. Zhang, “An experimental study on the mechanical property of the gas-filled coal," Journal of Chongqing University, vol. 5, pp. 42-47, 1993.

[15] W. Shen and B. Zhang, "Testing study on mechanical parameters of coal," Chinese Journal of Rock Mechanics and Engineering., vol. 19, Supplement 1, pp. 860-862, 2000.

[16] J. Xu, D. Zhang, S. Peng, D. Liu, and L. Wang, "Experimental study on the influence of temperature on mechanical properties of coal containing methane," Chinese Journal of Rock Mechanics and Engineering, vol. 30, Supplement 1, pp. 27302735, 2011.

[17] H. Xie, F. Gao, H. Zhou, H. Cheng, and F. Zhou, "On theoretical and modeling approach to mining-enhanced permeability for simultaneous exploitation of coal and gas," Journal of China Coal Society, vol. 38, no. 7, pp. 1101-1108, 2013.

[18] H. Xie, H. Zhou, J. Liu, and D. J. Xue, "Mining-induced mechanical behavior in coal seams under different mining layouts," Journal of China Coal Society, vol. 36, no. 7, pp. 10671074, 2011.

[19] J. Zuo, H. Xie, A. Wu, and J. Liu, "Investigation on failure mechanisms and mechanical behaviors of deep coal-rock single body and combined body," Chinese Journal of Rock Mechanics and Engineering, vol. 30, Supplement 1, pp. 2730-2735, 2011.

[20] P. Hou, X. Liang, Y. Zhang, J. He, F. Gao, and J. Liu, “3D multiscale reconstruction of fractured shale and influence of fracture morphology on shale gas flow," Natural Resources Research, vol. 30, no. 3, pp. 2463-2481, 2021.

[21] P. Hou, X. Liang, F. Gao, J. Dong, J. He, and Y. Xue, "Quantitative visualization and characteristics of gas flow in $3 \mathrm{D}$ pore- 
fracture system of tight rock based on Lattice Boltzmann simulation," Journal of Natural Gas Science and Engineering, vol. 89, no. 4, article 103867, 2021.

[22] J. Ren, Z. Song, B. Li, J. Liu, R. Lv, and G. Liu, "Structure feature and evolution mechanism of pores in different metamorphism and deformation coals," Fuel, vol. 283, article 119292, 2021.

[23] B. Nie, X. Liu, L. Yang, J. Meng, and X. Li, "Pore structure characterization of different rank coals using gas adsorption and scanning electron microscopy," Fuel, vol. 158, pp. 908917, 2015.

[24] H. Wang, E. Wang, Z. Li et al., "Study on safety pressure of water jet breaking coal based on the characteristic analysis of electromagnetic radiation signal," Process Safety and Environmental Protection., vol. 144, pp. 284-296, 2020.

[25] L. Si, Z. Li, Y. Yang et al., "Modeling of gas migration in waterintrusion coal seam and its inducing factors," Fuel, vol. 210, pp. 398-409, 2017.

[26] C. Mu and H. Wang, "Damage mechanism of coal under high pressure water jetting," Rock and Soil Mechanics., vol. 34, no. 5, pp. 1515-1520, 2013.

[27] Q. Yao, T. Chen, M. Ju, S. Liang, Y. Liu, and X. Li, “Effects of water intrusion on mechanical properties of and crack propagation in coal," Rock Mechanics and Rock Engineering, vol. 49, no. 12, pp. 4699-4709, 2016.

[28] W. Wang, X. Li, B. Lin, and C. Zhai, "Pulsating hydraulic fracturing technology in low permeability coal seams," International Journal of Mining Science and Technology., vol. 25, no. 4, pp. 681-685, 2015.

[29] T. Wang, H. Zhao, Y. Li, H. Zhang, and N. Ju, "Simulation and experimental study on the discontinuous dynamic impact on unidirectional confined coal-rock damage," Shock and Vibration., vol. 2019, article 9379563, pp. 1-15, 2019.

[30] F. Li, Y. Zhang, S. Fang, L. Zhang, and J. Liu, "Dynamic damage characteristics of elastic and plastic combination coal under impact loading," Journal of Mining and Safety Engineering, vol. 33, no. 6, pp. 1096-1109, 2016.

[31] X. Kong, E. Wang, S. Li, H. Lin, Z. Zhang, and Y. Ju, “Dynamic mechanical characteristics and fracture mechanism of gasbearing coal based on SHPB experiments," Theoretical and Applied Fracture Mechanics, vol. 105, article 102395, 2020.

[32] C. Mu and N. Gong, "Damage mechanism of coal under impact loads," Journal of China Coal Society, vol. 42, no. 8, pp. 2011-2018, 2017.

[33] K. Zheng, B. Qiu, Z. Wang, J. Li, and K. Gao, "Modelling heterogeneous coal-rock (HCR) failure patterns under dynamic impact loads using image-based finite element (FE) and discrete element (DE) model," Powder Technology, vol. 360, pp. 673-682, 2020.

[34] K. Zheng, B. Qiu, Z. Wang, X. Li, J. Li, and K. Gao, "Imagebased numerical study of three-dimensional meso-structure effects on damage and failure of heterogeneous coal-rock under dynamic impact loads," Particuology, vol. 51, pp. 132$141,2020$.

[35] E. Wang, X. Kong, X. He, J. Feng, Y. Ju, and J. Li, “Dynamics analysis and damage constitute equation of triaxial coal mass under impact load," Journal of China Coal Society., vol. 44, no. 7, pp. 2049-2056, 2019.

[36] J. Zhang, S. Guo, X. Zhang, L. Wang, Y. Cao, and G. Liu, "Dynamic damage constitutive model of plastic hardeningsoftening process of coal under impacting load," Journal of China Coal Society, vol. 2021, pp. 1-11, 2021.
[37] S. Gong, Y. Zhao, Z. Wang, L. Zhou, D. Yang, and W. Wang, "Effect of bedding structure on the energy dissipation characteristics of dynamic tensile fracture for water-saturated coal," Journal of China Coal Society., vol. 2021, pp. 1-10, 2021.

[38] L. Minmin, L. Weimin, and Y. Gaowei, "Fractal and pore structure analysis of structural anisotropic coal under different impact loads," Environmental Earth Sciences, vol. 79, no. 13, 2020.

[39] H. Zhao, Y. Liu, and X. Zhang, "The damage of dynamic impact on coal and rock under bidirectional static load constraint," Journal of Mining and Safety Engineering, vol. 38, 2021.

[40] H. Zhao, D. Ji, J. Li, T. Wang, and Y. Liu, "Study on the effect of impact loads on progressive failure of coal samples under unilateral and biaxial constraints," Chinese Journal of Rock Mechanics and Engineering., vol. 40, no. 1, pp. 53-64, 2021.

[41] H. Zhao, Z. Wang, and G. Hu, "Effects of dynamic loads on internal microstructure of coal by nuclear magnetic resonance(NMR)," Chinese Journal of Rock Mechanics and Engineering., vol. 35, no. 8, pp. 1569-1577, 2016.

[42] C. Jiang, M. Duan, G. Yin et al., "Experimental study on seepage properties, $\mathrm{AE}$ characteristics and energy dissipation of coal under tiered cyclic loading," Engineering Geology, vol. 221, pp. 114-123, 2017.

[43] Y. Liu, "Experimental analysis of coal permeability evolution under cyclic loading," Journal of China Coal Society., vol. 44, no. 8, pp. 2579-2588, 2019.

[44] Q. Li, Y. Liang, and Q. Zou, "Seepage and damage evolution characteristics of different gas-bearing coal under cyclic loading-unloading conditions," Journal of China Coal Society., vol. 44, no. 9, pp. 2803-2815, 2019.

[45] J. Zou, W. Chen, D. Yang, J. Yuan, and X. Tan, "Mechanical properties and damage evolution of coal under cyclic loading conditions," Journal of China Coal Society., vol. 41, no. 7, pp. 1675-1682, 2016.

[46] C. Zhong, Z. Zhang, P. G. Ranjith, Y. Lu, and X. Choi, "The role of pore water plays in coal under uniaxial cyclic loading," Engineering Geology, vol. 257, p. 105125, 2019.

[47] Z. Zhang, E. Wang, N. Li, X. Li, X. Wang, and Z. Li, "Damage evolution analysis of coal samples under cyclic loading based on single-link cluster method," Journal of Applied Geophysics, vol. 152, pp. 56-64, 2018.

[48] Z. Zhang, S. Li, E. Wang, X. Liu, and Y. Zhang, "Research on the damage evolution characteristics of coal based on cluster analysis of temporal-spatial dimension of acoustic emission events," Chinese Journal of Rock Mechanics and Engineering., vol. 39, no. S2, pp. 3338-3347, 2020.

[49] Y. Li, S. Zhang, and Z. Wen, "Energy conversion and fragment distribution characteristics of coal sample under uniaxial cyclic loading," Journal of China Coal Society., vol. 44, no. 5, pp. 1411-1420, 2019.

[50] Z. Zhang, C. Zhong, K. Xue, and Q. Qin, "Mechanical mechanism of pore fluid on coal dynamic disasters under cyclic loading," Journal of China Coal Society., vol. 46, no. 2, pp. 466-476, 2021.

[51] Q. Xu, Y. Yu, R. Liu, W. Cheng, and H. Yang, "Study on dynamic damage characteristics of coal under alternating hydraulic pressure," Bulletin of Engineering Geology and the Environment., vol. 80, no. 3, pp. 2385-2397, 2021.

[52] X. Liang, P. Hou, Y. Xue, X. Yang, F. Gao, and J. Liu, “A fractal perspective on fracture initiation and propagation of reservoir 
rocks under water and nitrogen fracturing," Fractals-Complex Geom. Patterns and Scaling in nature and Society, vol. 29, no. 7, 2021.

[53] C. Li, H. Yao, C. Xin, H. Li, J. Guan, and Y. Liu, "Changes in pore structure and permeability of middle-high rank coal subjected to liquid nitrogen freeze-thaw," Energy \& Fuels., vol. 35, no. 1, pp. 226-236, 2021.

[54] H. Li, L. Wang, H. Zhang, C. Zhang, H. Zhou, and Y. Geng, "Investigation on damage laws of loading coal samples under cyclic cooling treatment," Journal of China Coal Society., vol. 42, no. 9, pp. 2345-2352, 2017.

[55] B. Lin, Z. Li, C. Zhai, Q. Bi, and Y. Wen, "Pressure relief and permeability-increasing technology based on high pressure pulsating hydraulic fracturing and its application," Journal of Mining and Safety Engineering., vol. 28, no. 3, pp. 452-455, 2011.

[56] X. Li, B. Lin, C. Zhai, G. Li, and G. Ni, "The mechanism of breaking coal and rock by pulsating pressure wave in single low permeability seam," Journal of China Coal Society, vol. 38, no. 6, pp. 918-923, 2013.

[57] H. Zhu, M. Zhang, B. Gu, and X. Shen, "Energy analysis of coal damage deformation under pulsating pore water pressure," Journal of Central South University (Science and Technology), vol. 45, no. 10, pp. 3657-3663, 2014.

[58] H. Zhu, M. Zhang, B. Gu, X. Shen, and S. Zhu, "Experimental analysis of damage deformation of low permeability and soft coal under pulsating water pressure," Journal of China Coal Society., vol. 39, no. 7, pp. 1269-1274, 2014.

[59] H. Zhu, M. Zhang, S. Zhu, B. Gu, and X. Shen, "Effect of triaxial compression on damage deformation of coal rock under pulsed pore water pressure," Rock and Soil Mechanics., vol. 36, no. 8, pp. 2137-2143, 2015.

[60] J. Chen, X. Li, H. Cao, and L. Huang, "Experimental investigation of the influence of pulsating hydraulic fracturing on preexisting fractures propagation in coal," Journal of Petroleum Science and Engineering, vol. 189, p. 107040, 2020.

[61] J. Wu, S. Zhang, P. Sun, H. Cao, and P. Chen, "Experimental study on acoustic emission characteristics in coal seam pulse hydraulic fracturing," Journal of Central South University (Science and Technology), vol. 48, no. 7, pp. 1866-1874, 2017.

[62] J. Wu, S. Zhang, H. Cao, M. Zheng, F. Qu, and C. Peng, "Experimental investigation of crack dynamic evolution induced by pulsating hydraulic fracturing in coalbed methane reservoir ${ }^{1}$," Journal of Natural Gas Science and Engineering, vol. 75, p. 103159, 2020.

[63] G. Ni, H. Xie, Z. Li, L. Zhuansun, and Y. Niu, "Improving the permeability of coal seam with pulsating hydraulic fracturing technique: a case study in Changping coal mine, China," Process Safety and Environmental Protection., vol. 117, pp. 565$572,2018$.

[64] G. Ni, K. Dong, S. Li, and Q. Sun, "Gas desorption characteristics effected by the pulsating hydraulic fracturing in coal," Fuel, vol. 236, pp. 190-200, 2019.

[65] X. Jingna, X. Jun, N. Guanhua, S. Rahman, S. Qian, and W. Hui, "Effects of pulse wave on the variation of coal pore structure in pulsating hydraulic fracturing process of coal seam," Fuel, vol. 264, p. 116906, 2020.

[66] P. Hou, F. Gao, Y. Ju et al., "Changes in pore structure and permeability of low permeability coal under pulse gas fracturing,"
Journal of Natural Gas Science and Engineering., vol. 34, pp. 1017-1026, 2016.

[67] Y. Liu, X. Wen, M. Jiang et al., "Impact of pulsation frequency and pressure amplitude on the evolution of coal pore structures during gas fracturing," Fuel, vol. 268, p. 117324, 2020.

[68] Q. Li, B. Lin, and C. Zhai, "The effect of pulse frequency on the fracture extension during hydraulic fracturing," Journal of Natural Gas Science and Engineering, vol. 21, pp. 296-303, 2014.

[69] X. Kong, E. Wang, X. He, E. Zhao, and C. Zhao, "Mechanical characteristics and dynamic damage evolution mechanism of coal samples in compressive loading experiments," Engineering Fracture Mechanics., vol. 210, pp. 160-169, 2019.

[70] X. Lai, S. Zhang, F. Cui, Z. Wang, H. Xu, and X. Fang, "Energy release law during the damage evolution of water-bearing coal and rock and pick-up of AE signals of key pregnancy disasters," Chinese Journal of Rock Mechanics and Engineering., vol. 39, no. 3, pp. 433-444, 2020.

[71] X. Lai, S. Zhang, J. Dai, Z. Wang, and H. Xu, "Multi-scale damage evolution characteristics of coal and rock under hydraulic coupling," Chinese Journal of Rock Mechanics and Engineering., vol. 39, no. S2, pp. 3217-3228, 2020.

[72] B. Li, Z. Wang, C. Ren, Y. Zhang, J. Xu, and J. Li, "Mechanical properties and damage constitutive model of coal under the coupled hydro-mechanical effect," Rock and Soil Mechanics, vol. 42, no. 2, 2021.

[73] C. Xu, Q. Fu, K. Wang, L. Yuan, X. Zhang, and S. Wang, "Effects of the loading methods on the damage-permeability aging characteristics of deep mining coal," Journal of China University of Mining and Technology., vol. 47, no. 1, pp. 197205, 2018.

[74] Y. Liu, G. Han, W. Wang, Z. Huo, and T. Meng, "Evolution mechanism of fracture structure of loaded coal under different unloading rates," Journal of China Coal Society, vol. 45, no. 11, pp. 166-176, 2020.

[75] H. Zhao, T. Wang, B. Su, H. Cheng, S. Liu, and Y. Li, "Evolution law of internal microstructures andsurface cracks of coal under local loading," Journal of China University of Mining and Technology., vol. 49, no. 2, pp. 227237, 2021.

[76] H. Chu, X. Yang, C. Wang, and W. Liang, "Study on the coal damage and fracture mechanism under multiple actions of blasting stress wave," Arabian Journal for Science and Engineering., vol. 26, no. 8, pp. 58-63, 2021.

[77] X. Bai, D. Wang, F. Tian, D. Zhang, H. Li, and F. Ren, "Permeability model of damaged coal under triaxial stress loadingunloading," Chinese Journal of Rock Mechanics and Engineering., vol. 40, no. 8, pp. 1536-1546, 2021.

[78] T. Rong, H. Zhou, L. Wang, W. Ren, and Y. Guo, “A damagebased permeability models of deep coal under mining disturbance," Rock and Soil Mechanics., vol. 39, no. 11, pp. 39833992, 2018.

[79] J. Zhong, Z. Wang, L. Wang, J. Zhao, W. Ren, and H. Zhou, "Characteristics of damage evolution of deep coal based on CT three-dimensional reconstruction," Journal of China Coal Society., vol. 44, no. 5, pp. 1482-1494, 2019.

[80] G. Wang, D. Han, X. Qin, Z. Liu, and J. Liu, “A comprehensive method for studying pore structure and seepage characteristics 
of coal mass based on 3D CT reconstruction and NMR," Fuel, vol. 281, p. 118735, 2020.

[81] F. Du, K. Wang, X. Dong, and J. Wei, "Numerical simulation of damage and failure of coal-rock combination based on CT three-dimensional reconstruction," Journal of China Coal Society., vol. 2021, pp. 1-12, 2021.

[82] G. Wang, X. Qin, J. Shen, Z. Zhang, D. Han, and C. Jiang, "Quantitative analysis of microscopic structure and gas seepage characteristics of low-rank coal based on CT threedimensional reconstruction of CT images and fractal theory," Fuel, vol. 256, p. 115900, 2019. 